\title{
Sorption Isotherm Model of Zinc (II) onto Thermally Treated Rice Husk
}

\author{
AHMAD FARHAN AHMAD TARMIZI' ${ }^{1}$ KEAT KHIM ONG ${ }^{2 *}$, \\ WAN MD ZIN WAN YUNUS ${ }^{1}$, ANWAR FITRIANTO ${ }^{3}$, MOHD LIP JABIT ${ }^{4}$, \\ ABDUL GHAPOR HUSSIN ${ }^{1}$ and CHIN CHUANG TEOH ${ }^{5}$
}

\author{
'Department of Defence Science, Faculty of Defence Science and Technology, \\ Universiti Pertahanan Nasional Malaysia, Kem Sungai Besi, 57000 Kuala Lumpur, Malaysia. \\ ${ }^{2}$ Department of Chemistry and Biology,Centre for Defence Foundation Studies, \\ Universiti Pertahanan Nasional Malaysia, Kem Sungai Besi, 57000 Kuala Lumpur, Malaysia. \\ ${ }^{3}$ Department of Mathematics, Faculty of Science, Universiti Putra Malaysia, Malaysia. \\ ${ }^{4}$ Technical Services Centre, Malaysian Agricultural Research and Development Institute (MARDI) \\ Headquarter, G. P.O. Box 12301, 50774 Kuala Lumpur, Malaysia. \\ ${ }^{5}$ Engineering Research Centre, Malaysian Agricultural Research and Development Institute, (MARDI) \\ Headquarter, G. P.O. Box 12301, 50774 Kuala Lumpur, Malaysia. \\ *Corresponding author E-mail: ongkhim@upnm.edu.my
}

http://dx.doi.org/10.13005/ojc/320555

(Received: June 10, 2016; Accepted: Augsut 04, 2016)

\begin{abstract}
Various modifications were used to convert waste materials into heavy metal sorbents. In this study, simple thermal treatment was applied on rice husk and its sorption potential to remove Zn (II) ions from aqueous solution was investigated. Equilibrium sorption data were evaluated with two commonly used isotherms i.e. Langmuir and Freundlich isotherms. Coefficient of determination $\left(R^{2}\right)$ of the models were used to determine the best fitted isotherm. The correlation coefficients were 0.9884 and 0.8496 for Langmuir and Freundlich isotherms, respectively, showing that the sorption was better described by Langmuir isotherm. In addition, the sorption process is found to be favourable as indicated by the separation factor $\left(R_{L}\right)$ value between 0 and 1 . The potential of thermally treated rice husk as a sorbent for the removal of $\mathrm{Zn}$ (II) ions from aqueous solution is recognised.
\end{abstract}

Keywords: Isotherm Model, Thermally Treated Rice Husk, Zn (II) lons.

\section{INTRODUCTION}

Heavy metals are toxic and hazardous pollutants in water due to their non-biodegradable and persistent behaviours in the environment ${ }^{1}$. Zinc is one of the heavy metals discharged from industrial effluents. Its harmful health effects including "metalfume fever", nausea, diarrhoea, depression, lethargy, 
seizures, and ataxia ${ }^{2}$. Consequently, the maximum acceptable concentration of $\mathrm{Zn}$ (II) in drinking water permitted by World Health Organization (WHO) is $0.05 \mathrm{mg} / \mathrm{L}^{3}$.

Different chemical and physical methods such as precipitations, ion exchange, filtration, and solvent extraction have been applied to remove heavy metals from wastewater. However, these methods have some drawbacks for examples high operational cost, low removal efficiency at low concentration, and producing toxic sludge that needs further treatment ${ }^{4}$. Nevertheless, adsorption is an alternative approach to treat toxic heavy metals since this method is widely used as it is cost effective process 5 . Various waste materials have been used as adsorbents for examples rapeseed waste ${ }^{6}$, coffee husks ${ }^{7}$, corn cob $^{8}$, alum sludge waste $^{9}$, and rice husk ${ }^{10}$.

Understand adsorption mechanism by adsorption isotherm study is important as it can shows the distribution of adsorbate molecules between the liquid phase onto the solid phase. Langmuir and Freundlich models are the common isotherm models used to correlate the adsorption equilibrium of heavy metals onto adsorbents ${ }^{12}$. Paduraru et al. ${ }^{6}$ and Oliveira et al. ${ }^{7}$ have shown that equilibrium data fitted well with Langmuir isotherm model compared to Freundlich in their investigations on adsorption of $\mathrm{Zn}$ (II) ions onto rapeseed and coffee husks, respectively.

According to Abdolali et al. ${ }^{11}$, pre-treatment of adsorbents can improve physical and chemical properties of adsorbents, which can enhance the adsorption capacity and prevent organic leaching. Hence, in this work, a simple treatment was applied on rice husk to produce thermally treated rice husk for sorption of $\mathrm{Zn}$ (II) ions from aqueous solution. Equilibrium isotherm of the sorption was investigated.

\section{MATERIALS AND METHODS}

\section{Chemicals}

Sodium hydroxide pellets, $1.0 \mathrm{M}$ hydrochloric acid and $1000 \mathrm{mg} / \mathrm{L}$ of zinc nitrate standard solutions were of analytical grade and obtained from Merck Company (Germany). Ultrapure water (resistivity of 18.2 M\&!.cm) used for rinsing glassware, dilutions and preparation of solutions was obtained from a Milli-Q water purification system (Millipore, Germany).

\section{Preparation of sorbent}

Rice husk collected from a local rice mill was grounded and washed with ultrapure water several times to eliminate impurities and to obtain constant $\mathrm{pH}$ before dried in an oven at $105^{\circ} \mathrm{C}$ for $24 \mathrm{~h}$. The dried rice husk was sieved to obtain particles size between 300 to $600 \mu \mathrm{m}$ and then heated in a furnace at $800^{\circ} \mathrm{C}$ for two hours. The thermally treated rice husk was then put in a desiccator for cooling before kept in a container for the adsorption experiments.

\section{Preparation of solutions}

Various concentrations of $\mathrm{Zn}$ (II) working solutions (30-180 mg/L) used for sorption experiments were prepared by dilutions of $1000 \mathrm{mg} / \mathrm{L}$ of $\mathrm{Zn}\left(\mathrm{NO}_{3}\right)_{2}$ standard solution with the ultrapure water. In order to adjust the $\mathrm{pH}$ of $\mathrm{Zn}$ (II) working solutions, $0.1 \mathrm{M}$ of $\mathrm{HCl}$ solution was prepared by diluting $1.0 \mathrm{M}$ of $\mathrm{HCl}$ solution, whereas $1.0 \mathrm{M} \mathrm{NaOH}$ solution was prepared by dissolving an accurate amount of sodium hydroxide pellet with the ultrapure water.

\section{Sorption study}

One hundred $\mathrm{mL}$ of $30 \mathrm{mg} / \mathrm{L}$ of $\mathrm{Zn}$ (II) solution which was adjusted to $\mathrm{pH} 6$ with $1.0 \mathrm{M}$ $\mathrm{NaOH}$ and /or $0.1 \mathrm{M} \mathrm{HCl}$ solutions, was mixed with $2 \mathrm{~g}$ of 300-600 $\mu \mathrm{m}$ particle size of thermally treated rice husk. The mixture was agitated at $150 \mathrm{rpm}$ for 180 minutes at $30^{\circ} \mathrm{C}$. After the contact time, the mixture was filtered using a $0.45 \mu \mathrm{m}$ cellulose nitrate membrane filter. The content of $\mathrm{Zn}$ (II) ions in the filtrate was analyzed using an inductively coupled plasma optical emission spectrometry (ICP-OES) (Perkin Elmer, OPTIMA 5300 DV). The sorption experiments were conducted in duplicates and repeated using $60,90,120,150$ and $180 \mathrm{mg} / \mathrm{L}$ of $\mathrm{Zn}$ (II) working solutions. The sorption capacity, $q_{i}$, was determined using equation (1):

$$
q_{t}(m g / g)=\frac{C_{o}-C_{e}}{m} \times V
$$

where $C_{o}$ and $C_{e}$ were initial and final concentrations (mg/L) of $\mathrm{Zn}$ (II) ions, respectively, $\mathrm{m}$ is the mass of sorbent $(\mathrm{g})$ and $\mathrm{V}$ is the volume of solution (L). 


\section{RESULTS AND DISCUSSION}

Adsorption isotherm models are applied to determine the interaction between adsorbent and adsorbate especially Langmuir and Freundlich isotherm models ${ }^{13}$. Hence, in this study, the equilibrium data were evaluated with these isotherm models. The coefficient of determination $\left(R^{2}\right)$ of the models were used to determine the best fitted isotherm model.

\section{Langmuir isotherm model}

Langmuir adsorption isotherm is widely used to describe the adsorption of organic and inorganic pollutants, such as dyes and heavy metals from aqueous solutions. It suggests that the adsorption onto the adsorbent surface is homogeneous, where the adsorption of solute from aqueous solution onto the adsorbent surface occurs as monolayer adsorption on the homogeneous number of exchanging sites ${ }^{14}$. Langmuir adsorption isotherm is expressed as below:

$$
\frac{C_{e}}{q_{e}}=\frac{1}{q_{\max } b}+\frac{C_{e}}{q_{\max }}
$$

where $q_{e}$ is the amount of metals adsorbed on the sorbent $(\mathrm{mg} / \mathrm{g})$ at equilibrium, $C_{e}$ is the concentration of metal solution at equilibrium, $q_{\max }$

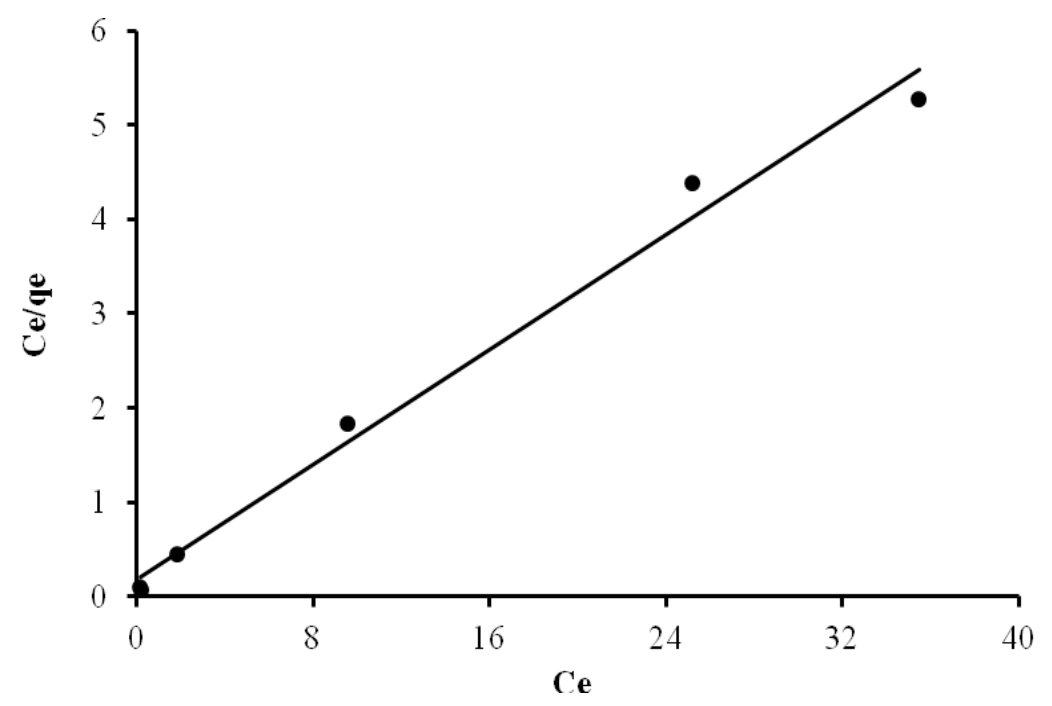

Fig. 1: Langmuir plot for sorption of $\mathrm{Zn}$ (II) ions

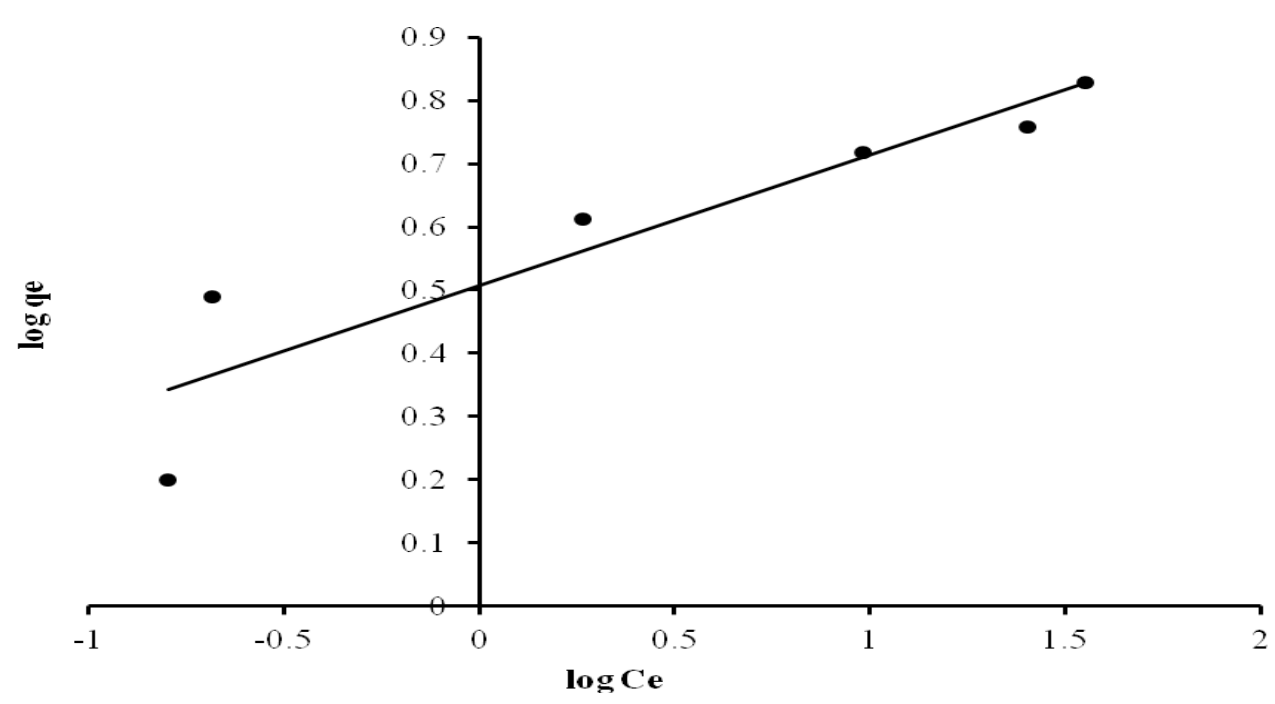

Fig. 2: Freundlich plot for sorption of Zn (II)ions 
Table 1: Langmuir and Freundlich sorption isotherm constants for Zn (II) ions

\begin{tabular}{llll}
\hline \multicolumn{2}{l}{ Langmuir constants } & Freundlich constants \\
\hline$q_{\max }(\mathrm{mg} / \mathrm{g})$ & 6.5574 & $K_{f}\left((\mathrm{mg} / \mathrm{g}) /(\mathrm{mg} / \mathrm{L})^{1 / \mathrm{n}}\right)$ & 3.2181 \\
$b(\mathrm{~L} / \mathrm{mg})$ & 0.8592 & $n$ & 4.8497 \\
$R^{2}$ & 0.9884 & $R^{2}$ & 0.8496 \\
\hline
\end{tabular}

is the maximum sorption capacity describing a complete monolayer sorption $(\mathrm{mg} / \mathrm{g})$ and $b$ is sorption equilibrium constant $(\mathrm{L} / \mathrm{mg})$ that is related to the free energy of sorption. The values of $q_{\max }$ and $b$ were determined from the linear plot of $C_{e} / q_{e}$ versus $C_{e}$. Figure 1 shows the Langmuir plot for sorption of $\mathrm{Zn}$ (II). The data obtained with the coefficients of determination $\left(R^{2}\right)$ was presented in Table 1. Equilibrium parameter, $R_{L}$ is a dimensionless constant separation factor to express the essential features and characteristics of Langmuir isotherm ${ }^{15,16}$. $\mathrm{R}_{L}$ can be defined as:

$$
R_{L}=\frac{1}{1+b C_{0}}
$$

where $b$ is sorption equilibrium constant $(\mathrm{L} / \mathrm{mg})$ that is related to the free energy of sorption and $C_{o}$ is initial concentration of $\mathrm{Zn}$ (II) ions (mg/L). The value of $R_{L}$ shows the sorption either unfavourable if $R_{L}>1$, linear if $R_{L}=1$, favourable if $0<R_{L}<1$, or irreversible if $R_{L}=0$. The $R_{L}$ values for the sorption of $\mathrm{Zn}$ (II) ions onto thermal treated rice husk using the lowest initial concentration (30 mg/L) and the highest initial concentration ( $180 \mathrm{mg} / \mathrm{L})$ were 0.037 and 0.0064 , respectively. The results proved that the sorption of $\mathrm{Zn}$ (II) ions using thermally treated rice husk is a favourable process.

\section{Freundlich isotherm model}

Freundlich isotherm model assumed that the adsorption process occurs from the interaction of the pollutant molecules on the heterogeneous surfaces. When the occupied binding sites increased, the energy of adsorption declined logarithmically ${ }^{14}$. Freundlich isotherm model used to evaluate the experimental was expressed by the following equation ${ }^{17}$.

$$
\log q_{e}=\log K_{f}+\frac{1}{n} \log C_{e}
$$

where $K_{f}$ is the Freundlich isotherm constant $(\mathrm{mg} / \mathrm{g})$ related to the bonding energy. $K_{f}$ and $n$ are constants and determined from the $\log q_{e}$ versus $\log C_{e}$ plot. The constants $K_{f}$ and $n$ were calculated using Freundlich plot as shown in Figure 2. The values for Freundlich constants and coefficient of determination $\left(R^{2}\right)$ for the sorption process are presented in Table 1. The value of $n$ between 1 and $10(1 / n$ less than 1$)$ indicates favourable adsorption ${ }^{16}$. From Table 1, the value of $\mathrm{n}$ is 4.8497 indicating that the sorption of $\mathrm{Zn}$ (II) is favourable.

From Table 1, the results showed that the sorption of $\mathrm{Zn}$ (II) onto thermally treated rice husk was better fitted to Langmuir isotherm model $\left(R^{2}=0.9884\right)$ compared to Freundlich isotherm model $\left(R^{2}=0.8496\right)$. These results proved that the sorption is monolayer with an equal activation energy and no interaction between sorbates on the adjacent active sites. Study by Elham et al. ${ }^{13}$ found that adsorption behaviour of $\mathrm{Zn}$ (II) onto rice husk was well described by Langmuir isotherm model, while sorption of $\mathrm{Zn}$ (II) by chemically prepared rice husk also follow Langmuir isotherm model ${ }^{10}$.

\section{CONCLUSION}

In this work, mechanisms of $\mathrm{Zn}$ (II) ions sorption were proposed based on equilibrium data obtained. The sorption was better described by Langmuir isotherm compared to Freundlich isotherm which suggests that the sorption of $\mathrm{Zn}$ (II) ions onto the sorbent surface is on monolayer. The sorption process was favourable as indicated by the separation factor $\left(R_{L}\right)$ value. Thermally treated rice 
husk can be a candidate of cost effective sorbent to remove $\mathrm{Zn}$ (II) ions from wastewater. This approach also might help to solve the problem of agricultural waste management.

\section{ACKNOWLEDGMENT}

The authors are grateful to Universiti Pertahanan Nasional Malaysia for the support to conduct this research work.

\section{REFERENCES}

1. Bilal, M.; Shah, J. A.; Ashfaq, T.; Gardazi, S. M. H.; Tahir, A. A.; Pervez, A.; Haroon, H.; Mahmood, Q.; Journal of Hazardous Materials. 2013, 263, 322- 333.

2. Malamis, S.; Katsou, E.; Journal of Hazardous Materials. 2013, 252- 253, 428- 461.

3. Mali, A.; Pandit V.; Majumder, D. R.; International Journal of Technical Research and Applications. 2014, 2, 42-46.

4. Matouq, M.; Jildeh, N.; Qtaishat, M.; Hindiyeh M.; Syouf, M. Q. A.; Journal of Environmental Chemical Engineering. 2015, 3, 775-784.

5. Regina, M. Y.; Saraswathy, S.; Kamal, B.; Karthik, V.; Muthukumaran, K.; Journal of Chemical and Pharmaceutical Sciences. 2015, 8, 1-6.

6. Paduraru, C.; Tofan, L.; Teodosiu, C.; Bunia, I.; Tudorachi, N.; Toma, O.; Process Safety and Environmental Protection. 2015, 94, 18-28.

7. Oliveira, W. E.; Franca, A. S.; Oliveira, L. S.; Rocha, S. D.; Journal of Hazardous Materials. 2008, 152, 1073-1081.

8. Buasri, A.; Chaiyut, N.; Tapang, K.; Jaroensin, S.; Panphrom, S.; APCBEE Procedia. 2012, 3, 60-64.
9. Ong, K. K.; Md Nor, M. A; Mohamad, S; Ahmad Nasaruddin, N; Jamari, N. A.; Wan Yunus, W. M. Z.; AIP Conf. Proc. 2015, 1660, 070055.

10. El-Shafey, E. I.; Journal of Hazardous Materials. 2010, 175, 319-327.

11. Abdolali, A.; Ngo, H. H.; Guo, W.; Zhou, J. L.; Du, B.; Wei, Q.; Wang, X. C.; Nguyen, P. D.; Bioresource Technology. 2015, 193, 477487.

12. Sadeek, S. A.; Negm, N. A.; Hefni, H. H. H.; Wahab, M. M. A.; International Journal of Biological Macromolecules. 2015, 81, 400409.

13. Elham, A.; Hossein, T.; Mahnoosh, H.; J. Appl. Sci. Environ. Manage. 2010, 14, 159-162.

14. Safa, Y.; Biosorption of Direct Dyes from Aqueous Solution Using Rice (oryza sativa) Husk, Vol. Doctor of Philosophy University of Agriculture, Faisalabad, 2010.

15. Dada, A. O.; Ojediran, J. O.; Olalekan, A. P.; Advances in Physical Chemistry. 2013, 2013, 1-6.

16. Naiya, T. K.; Bhattacharya, A. K.; Mandal, S.; Das, S. K.; Journal of Hazardous Materials. 2009, 163, 1254-1264.

17. Freundlich, H.; Phys. Chem. Soc. 1906, 40, 1361-1368. 